\title{
ANALYSIS OF PHTHALATE AND PRIORITY PHENOLS FROM A WASTEWATER TREATMENT PLANT IN CAPE TOWN, SOUTH AFRICA
}

\author{
Olanrewaju Olujimi \\ Olalekan Fatoki \\ James Odendaal
}

Faculty of Applied Sciences, Cape Peninsula University of Technology, South Africa Corresponding address: olujimio@.cput.ac.za

\begin{abstract}
Continuous disposal of endocrine-disrupting chemicals (EDCs) into the environment can lead to serious human health problems and can affect aquatic organisms. A number of investigations suggested that final effluents of wastewater treatment plants are the main source of EDCs into the aquatic environment. A developed analytical method was used for the analysis of priority phenols as tert-butyl derivatives and phthalates in wastewater. Qualitative and quantitative analyses were performed by gas chromatography - mass spectrometry (GC-MS) using DB-5MS column. These compounds were evaluated using solid-phase extraction for raw and treated wastewater from a wastewater treatment plant. Concentrations of analytes ranged from below limit of detection to $570 \mu \mathrm{gL}^{-1}$ for phenols and below limit of quantification to $796 \mu \mathrm{gL}^{-1}$ for phthalates. Diethyl phthalate was the most prominent phthalate ester with pentachlorophenol for the corresponding phenol. The average percent removal varied from 52.63 to $100 \%$. The result clearly shows that environmental endocrine disrupting chemicals are not completely removed from treated wastewater.
\end{abstract}

\section{KEYWORDS}

Priority phenols, phthalate, wastewater, EDCs

\section{INTRODUCTION}

Endocrine disrupting chemicals (EDCs) have emerged as a major environmental issue in the last decade. They are commonly found in environmental matrices like waters, sediments and soils due to their wide industrial consumption. These compounds are generated from several sources such as production of plastic, dyes, drugs, pesticides, antioxidants, paper and biodegradation of many chlorinated phenoxyacids, phenoxyalkanoic acid, herbicides and organophosphorus herbicides $[1,2]$. They cause toxicity, persistence and bioaccumulation in animals and plants. Furthermore, a reduction of fecundity and fertilization rate in fish due to EDCs may be dangerous for human health $[3,32]$.

Phenols are widespread pollutants, though they are biodegradable in water and soil. They are found in water for a long period of time if large amounts are released over a long time or if 
low amount are released over an extended time period [28]. Pentachlorophenol (PCP) one of the classified priority phenols is used as a wood preservative $[2,4,5]$. Phenol is generated from lignin degradation in paper production and chlorophenols can be generated from chlorination of drinking water. Nitrophenols are formed photochemically in the atmosphere from vehicle exhaust and from degradation of ammunition wastes $[6,7,8]$. Phenols are toxic, carcinogenic and mutagenic compounds [29]. They were recently grouped as important source of environmental pollutants due to their toxicity at low environmental concentrations [31].

Phthalates, on the other hand, are mostly used in plasticizers, pesticides, fragrances and lubricants, perfumes, lotions and cosmetics [9, 10, 11, 12]. Phthalates, which are not chemically bound to the polymer matrices, may easily be dispersed into the environment at different stages: production, use or after disposal. Phthalates are rather ubiquitous and their occurrence has been reported in different compartments of the environment: atmosphere, surface water, sediment and sewage sludge. Research had showed that phthalates are environmental hormones are harmful to human resulting in instability of internal secretion and procreation ability [9], anovulation and decreased fetal growth and hepatic and renal effects [13].

Recent concerns about the hazardous nature and environmental dangers of organic solvents applied in environmental sample preparations have led to the development of several extraction techniques that are free of organic solvents or only use low volumes of these solvents, such as solid phase extraction [14, 15], solid-phase microextraction (SPME) [16, 17, 18], supercritical fluid extraction (SFE), subcritical water extraction (SBWE), microwaveassisted extraction (MAE) and spectrophotometric method [30].

Industrial, agricultural and municipal waste often contains diverse levels of EDCs resulting in exposure to organisms at concentrations that could elicit biological effects. Municipal and industrial wastewater treatment plants encounter a range of EDCs which sometimes are able to pass through the wastewater treatment system to receiving water bodies.

Priority phenols and phthalates are usually determined separately in the same environmental matrix using standard protocols which are often time consuming and requires large amount of organic solvents. The aim of this study was to determine the occurrence and removal efficiency of a wastewater treatment plant at removing phenols and phthalates from final treatment effluent.

\section{MATERIAL AND METHODS}

\subsection{Chemicals and reagents}

Analytes evaluated in this study includes 11 priority phenols and 6 phthlates on the USEPA list. Analytical grade of phenol (P-OH) 99.9\%, 2-nitrophenol (2-NP) 99\%, nitrophenol (4-NP) 99\%, 2,4-dinitrophenol (2,4-DNP) 99.7\%,2-chlorophenol (2-CP) 99.8\%, 4,6-dinitro-2-methylphenol (DNMP) 98\%, 2,4-dimethylphenol (2,4-DMP) 98\%, 4chlorophenol (4-CP) 99\%, 2,4-dichlorophenol (2,4-DCP) 100\%, pentachlorophenol (PCP) 99.6\%, 4-chloro-3-methylphenol (4-C-3MP) 99\%, dimethyl phthalate (DMP), diethyl phthalate (DEP), benzybutyl phthalate (BBP), dioctyl phthalate (DOP), diethylhexylphthalate (DEHP), dibutyl phthalate (DBP) were purchased from Supelco (Bellefonte, PA USA). The solvents (methanol, n-hexane, acetone and acetonitrile) were of analytical grade from Sigma Aldrich and were further purified by distillation. Separate stock solutions of individual analytes were prepared in methanol $(1000 \mathrm{mg} / \mathrm{L})$. A working mixture containing each compound at $10 \mathrm{mg} / \mathrm{L}$ was also prepared and stored at $4^{\circ} \mathrm{C}$ in darkness. Milli-Q water used was from Millipore (Bedford, MA, USA). 
An Agilent 6890N gas chromatograph/5975 mass selective detector system operating at $70 \mathrm{eV}$ with ion source temperature set at $230^{\circ} \mathrm{C}$ was used for this study. The gas chromatograph was equipped with a DB-5MS fused silica column (phenyl methyl siloxane) (30 m x $0.25 \mathrm{~mm}$ i.d.; 0.25 um film thickness. The injector temperature and GC-MS interface temperature were maintained at 260 and $280^{\circ} \mathrm{C}$, respectively. The sample was introduced into the gas chromatograph in splitless mode and the helium carrier gas flow rate was set at $1.0 \mathrm{ml} / \mathrm{min}$. The oven temperature of the $\mathrm{GC}$ was set at $80^{\circ} \mathrm{C}$ for $1 \mathrm{~min}$, then increased to $280^{\circ} \mathrm{C}$ at $25 \mathrm{C} / \mathrm{min}$ and held for $7 \mathrm{~min}$. The post run temperature was set at $300^{\circ} \mathrm{C}$ for 2 min to clean up the column before the next injection.

\subsection{Sample Collection}

This study investigated a wastewater treatment plant in Cape Town for its efficiency at phenols and phthalates removal in the final effluent. Grab samples were collected from the plant at peak hours $(09: 00 ; 12: 00$ and 15:00) for 3 consecutive days. A total of 54 samples comprising of raw and final effluents were collected in $500 \mathrm{~mL}$ pre-cleaned amber glass bottles with methanol to prevent analytes from adhering onto glass wall [19]. Sample bottles were kept cold on ice while transporting to back to the laboratory. Once received in the laboratory, samples were extracted and analyzed within 12 hours of collection.

\section{$2.4 \quad$ Solid phase extraction procedure}

C18-E cartridges (strata) containing $500 \mathrm{mg} / 6 \mathrm{ml}$ from separations were used for the extraction of phenols and phthalates from aqueous. Prior to sample processing, the cartridges were fitted onto a vacuum manifold (Supelco) connected to pump and the cartridges were conditioned with $5 \mathrm{~mL}$ of $\mathrm{n}$-hexane:acetone $(50: 50, \mathrm{v} / \mathrm{v})$, followed sequentially $5 \mathrm{~mL}$ of methanol and 10mL of Milli-Q purified water (purified by Milli-Q Synthesis A 10 System, Millipore, Bedfore, MA, USA). Prior to extraction of each $500 \mathrm{~mL}$, water samples were filtered on vacuum using a $0.22 \mu \mathrm{m}$ to remove suspended particulate matter that might block the SPE cartridges. Hydrochloric acid (37\%) was used to adjust the $\mathrm{pH}$ of the water sample to a $\mathrm{pH}$ of between 2 and 3 before passing it through the conditioned cartridge. After the sample was passed through the cartridge, $5 \mathrm{~mL}$ of Milli-Q was passed through and left on the vacuum manifold for $30 \mathrm{~min}$ to dry $(-70 \mathrm{Kpa})$. The retained analytes of interest were eluted with $3.5 \mathrm{~mL}$ of methanol followed by $3.5 \mathrm{~mL}$ of $\mathrm{n}$-hexane:acetone $(50: 50, \mathrm{v} / \mathrm{v})$ into $10 \mathrm{~mL}$ glass vial. This was blown to dryness on hot plate at $70^{\circ} \mathrm{C}$ under gentle flow of nitrogen followed by derivatization.

\section{$2.5 \quad$ Derivatization procedure}

The dried eluent was reconstituted with $50 \mu \mathrm{L}$ acetonitrile and N-Methyl-N- (TertButyldimethylsilyl) trifluoroacetamide (MTBSTFA) of the derivatising reagent was added and the mixture was vortex mix for $90 \mathrm{~s}$. This was derivatized at $90^{\circ} \mathrm{C}$ for $20 \mathrm{~min}$ in $\mathrm{GC}$ oven according to Olujimi et al. (2010) [27]. The sample was cool down to room temperature and $1 \mu \mathrm{L}$ was injected into GC-MS for analysis. 
Procedural blanks spiked, solvent blanks and control samples were included in each batch of analyses. Blanks and controls were treated in the same manner as the samples were always analyzed after every sample injection. A calibration standard solution of $50 \mu \mathrm{gL}^{-1}$ was injected in duplicate to monitor the instrumental sensitivity and reproducibility every time before sample analyses.

\subsection{RESULTS AND DISCUSSION}

\subsection{Calibration and validation of analytical method}

External calibration was used to quantify extracts. Calibration was by plotting peaks area versus amount injected. Linearity of the system was measured at 4-5 points. Calibration ranged from 2.5 to $1000 \mu \mathrm{gL}^{-1}$. Calibration curves were linear over the range of interest with a correlation coefficient ranging from 0.976 to 1.00 (Table 1). Due to non-availability of reference materials, the trueness of the analytical method for extraction and elution was assessed through recovery of additions of standard mixtures of the target analytes in Milli-Q. Figure 1 shows the chromatogram of the derivatized products. The limit of quantification of the proposed method was calculated using signal-to-noise ratio of 10 . The percentage recovery, retention time and ions monitored for the target analytes were presented in Table 2. The percentage recovery of the solid phase extraction ranged from $73.21 \pm 0.05(2,4,6$-TCP) to $101.32 \%$ (DEHP).

\subsection{Occurrence and removal of Phthalates in the wastewater treatment plant}

All the phthalate esters investigated were detected in raw and final effluent except DMP which was neither detected in raw nor final effluent. The average concentrations of phthalate in both the influent and effluent of the treatment plant are presented in Table 3. The average flow rate during the sampling campaign was $20765 \mathrm{~m}^{3} \mathrm{~d}^{-1}$. DEP was the most abundant phthalate $\left(796 \mu \mathrm{gL}^{-1}\right)$ followed by DBP $\left(123 \mu \mathrm{gL}^{-1}\right)$ and DEHP $\left(57 \mu \mathrm{gL}^{-1}\right)$. The occurrence pattern of phthalates in raw and final effluent differs from previous work where DEHP is reported to be higher than other phthalates [20, 21, 22]. However, the result is in tandem with the study of Oliver et al. (2005) where DEP was reported higher than other phthalates in primary tank [23]. The percentage of phthalates in the treatment plant was about $45 \%$ of the total samples.

Removal of phthalates from the treatment plant ranges from $52.63 \%$ (DEHP) to $100 \%$ for most of the phthalates. Intra and inter day study of the samples collected at 09:00; 12:00 and 15:00 (peak time) show similar removal efficiency for the treatment plant. The removal efficiency could be attributed to the sedimentation of solids and in the activated sludge which was not investigated. The level of phthalates detectable in the raw and effluent are higher than in other studies [20, 21, 23, 24, 25]. Throughout the three days sampling period, DEP concentration was higher than other phthalates investigated in the treatment plant.

\subsection{Occurrence and removal of Phenols in the wastewater treatment plant}

PCP is the most abundant of the phenols investigated with an average concentration of $570 \mu \mathrm{gL}^{-1}$ in the plant investigated. The occurrence pattern is in the order of PCP $>2 \mathrm{M}-4,6 \mathrm{DNP}>2 \mathrm{CP}>\mathrm{POH}>2 \mathrm{NP}$. The occurrence pattern of the 11 priority phenol has not been investigated in these wastewater treatment plants before now. Generally, phenols were more pronounced in raw effluent than corresponding phthalates. The level of phenols in the 
treatment plant could be attributed to waste from industries as the plant receives both domestic and industrial waste.

Table 1: Limits of detection, limits of quantification and correlation coefficient of analytes.

\begin{tabular}{llll}
\hline Compound & LOD $\left(\mu \mathrm{gL}^{-1}\right)$ & $\mathrm{LOQ}\left(\mu \mathrm{gL}^{-1}\right)$ & $\left(\mathrm{R}^{2}\right)$ \\
\hline $\begin{array}{l}\text { P-OH } \\
\text { 2-CP }\end{array}$ & 2.2 & 7.18 & 1.000 \\
DMP* & 2.2 & 7.43 & 0.993 \\
2,4-DMP & & & \\
4-C, 3-MP & & & \\
DEP* & & \\
2,4-DP & & & \\
2-NP & & & 1.000 \\
4-NP & 1.36 & 4.47 & 0.999 \\
2,4,6-TCP & 2.81 & 9.63 & \\
DBP* & & & 0.986 \\
2,4-DNP & 1.63 & 5.36 & \\
2-M, 4,6-DNP & & & 0.998 \\
PCP & 2.23 & 7.37 & 0.987 \\
BBP* & 0.9 & 2.9 & \\
DEHP* & & & \\
DOP* & 1.41 & 4.65 & \\
\hline & & & \\
\hline
\end{tabular}


Table 2: Retention times, target ions and recoveries of selected phenols and phthalates $(n=7)$

\begin{tabular}{|c|c|c|c|c|}
\hline Compound & $\begin{array}{l}\text { Retention } \\
\text { Time (min) }\end{array}$ & $\begin{array}{l}\text { Primary } \\
\text { ion }(\mathrm{m} / \mathrm{z})\end{array}$ & $\begin{array}{l}\text { Secondary } \\
\text { ion }(\mathrm{m} / \mathrm{z})\end{array}$ & $\begin{array}{l}\text { SPE Recovery } \\
(\%)\end{array}$ \\
\hline $\mathrm{P}-\mathrm{OH}$ & 11.12 & 151 & 208 & $93.43 \pm 0.05$ \\
\hline 2-CP & 15.21 & 185 & 149,93 & $98.21 \pm 4.38$ \\
\hline DMP* & 15.27 & 163 & 77 & $83.72 \pm 6.03$ \\
\hline 2,4-DMP & 15.74 & 179 & $163,149,105$ & $98.69 \pm 8.43$ \\
\hline 4-C, 3MP & 17.71 & 199 & 93 & $76.21 \pm 5.28$ \\
\hline DEP* & 18.38 & 149 & $177,104,77$ & $98.46 \pm 11.31$ \\
\hline 2,4-DCP & 18.81 & 219 & $183,125,93$ & $94.1 \pm 7.16$ \\
\hline 2-NP & 19.15 & 196 & $180,151,136$ & $95.39 \pm 11.68$ \\
\hline 4-NP & 20.74 & 196 & 150,135 & $88.19 \pm 10.29$ \\
\hline 2,4,6-ТCP & 20.76 & 255 & $217,159,93$ & $73.21 \pm 0.05$ \\
\hline $\mathrm{DBP} *$ & 22.89 & 149 & 207 & $98.99 \pm 8.27$ \\
\hline 2,4-DNP & 23.39 & 241 & $225,195,137$ & $96.34 \pm 2.93$ \\
\hline 2-M,4,6DNP & 24.29 & 255 & 239, 209 179, & $90.33 \pm 6.18$ \\
\hline PCP & 24.58 & 323 & 93 & $92.64 \pm 11.39$ \\
\hline BBP* & 26.09 & 149 & 206,91 & $97.43 \pm 18.31$ \\
\hline DEHP* & 27.35 & 149 & 279,167 & $101.32 \pm 0.21$ \\
\hline DOP* & 29.01 & 149 & 279,57 & $90.77 \pm 5.39$ \\
\hline
\end{tabular}

*Compound not affected by MTBSTFA derivatization 
Linnaeus ECO-TECH '10

Kalmar, Sweden, November 22-24, 2010

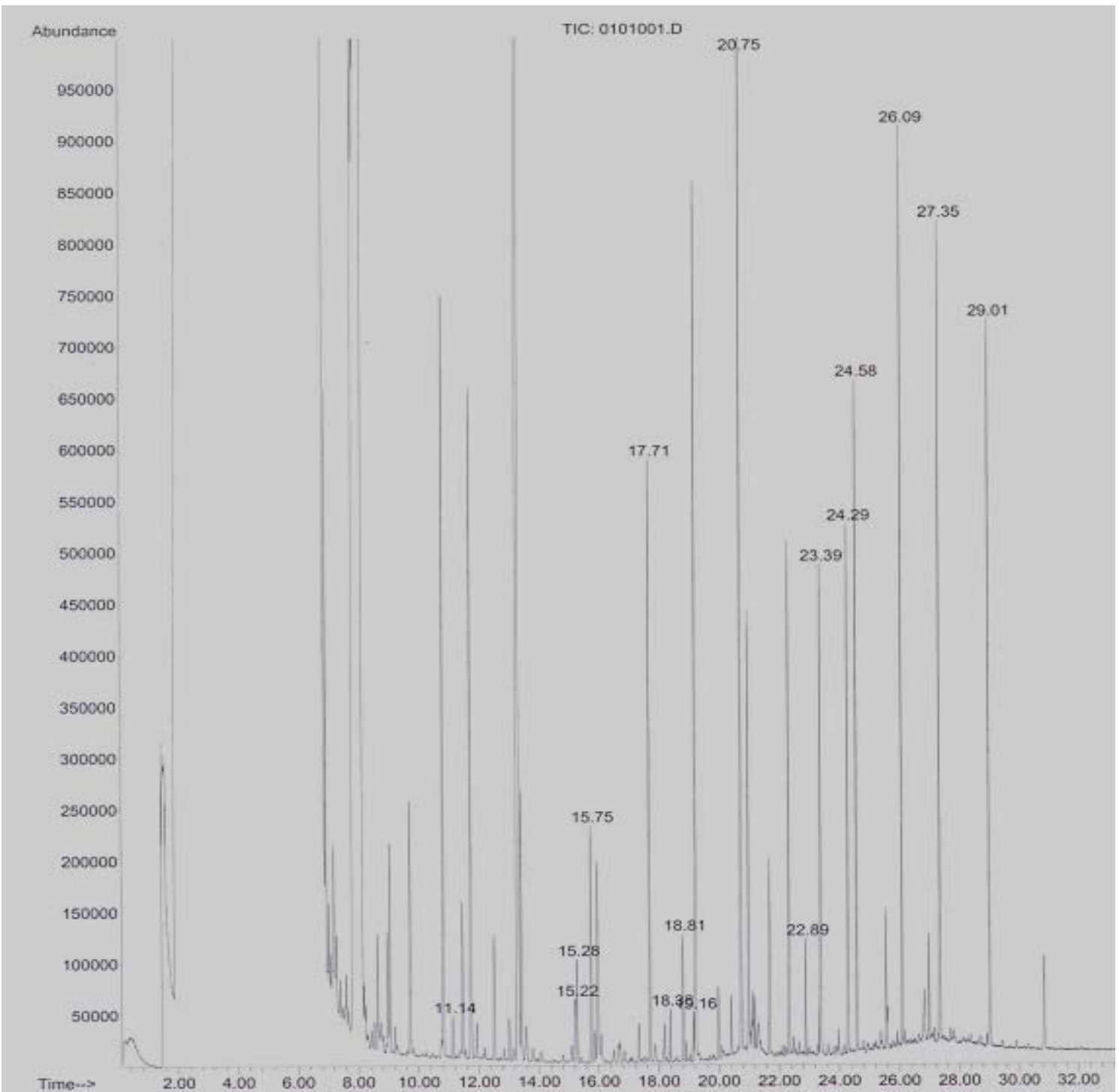

Fig 1: Chromatogram of derivatized phenols and phthalate esters $20.75 \quad(2,4,6-$ Trichlorophenol + 4-Nitrophenol) 
Table 3: Concentrations of phenol and phthalates in the wastewater treatment plant (Mean \pm STD) $\left(\mu g l^{-1}\right)$

\begin{tabular}{lccc} 
Compound & Influent & Effluent & $\%$ Removal \\
\hline P-OH & $163 \pm 10$ & nd & 100 \\
$2-\mathrm{CP}$ & $180 \pm 40$ & nd & 100 \\
DMP* & nd & nd & - \\
2,4-DMP & bdl & $130 \pm 80$ & -100 \\
4-C, 3-MP & 30 & nd & 100 \\
DEP* & $796 \pm 430$ & $150 \pm 80$ & 81.16 \\
2,4-DCP & nd & nd & 100 \\
2-NP & $120 \pm 10$ & 53 & 55.83 \\
$4-N P$ & bql & nd & 100 \\
2,4,6-TCP & bql & nd & 100 \\
DBP* & $123 \pm 2$ & nd & 100 \\
2,4-DNP & $20 \pm 10$ & nd & 100 \\
2-M, 4,6-DNP & $350 \pm 295$ & nd & 100 \\
PCP & $570 \pm 90$ & nd & 100 \\
BBP* & $50 \pm 27$ & nd & 100 \\
DEHP* & 57 & 20 & 64.91 \\
DOP* & $10 \pm 1$ & bql & $\leq 100$ \\
& & &
\end{tabular}

*Compound not affected by MTBSTFA derivatization; $n d=$ not detected; blq = below quantification limit

The average plant removal efficiency varied from 64.91 (2NP) to $100 \%$ for most of the phenols. 2,4-dimethyl phenol was below detection limit in the influent but was detected at a concentration of $130 \mu \mathrm{gl}^{-1}$ in the effluent. Also, 4-Nitrophenol and 2,4,6-Trichlorophenol were detected but their concentrations were below quantification limits. The observed concentrations in the plant are higher than the set local and international standards.

\subsection{CONCLUSION}

The need of ensuring the protection of water resources requires the knowledge of occurrence and removal of pollutants that are continuously released into wastewater treatment plants. This study will lay a foundation for further monitoring of phenol and phthalates at different stages of WWTPs to establish the fate of analytes in WWTPs. 


\section{ACKNOWLEDGEMENT}

We were thankful to National Research Foundation and Cape Peninsula University of Technology for financial support given to Mr. Olanrewaju Olujimi for his doctoral degree.

\subsection{REFERENCES}

[1] Vidal, J.L., Vega, A.B., Frenich, A.G. Gonzalez, F.J.E. Liebana, F.J.A. 2004. Determination of fifteen priority phenolic compounds in environmental samples from Andalusia (Spain) by liquid chromatography-mass spectrometry. Anal Bioanal Chem $379: 125-130$

[2] Santana, C.M., Ferrera, Z.S. Rodriguez, J.J.S. 2005. An environmentally friendly method for the extraction and determination of priority phenols in soils using microassisted micellar extraction. Anal Bioanal Chem 382: 125-133.

[3] Peng, X., Wang, Z., Yang, C., Chena, F., Maia, B. 2006. Simultaneous determination of endocrine-disrupting phenols and steroid estrogens in sediment by gas chromatography-mass spectrometry. Journal of Chromatography. 1116: 51-56.

[4] Schummer, C., Delhomme, O., Appenzeller, B.M.R., Wennig, R., Millet, M. 2009. comparison of MTBSFA and BSTFA in derivation reaction of polar compounds prior to GC/MS analysis. Talanta 77: 1473-1482.

[5] Grynkiewicz, E., Polkowska, Z., Kot-Wasik, A. Namiesnik, J. 2002. Determination of phenols in runoff. Polish journal of environmental studies. Vol. 11 (1): 85-89.

[6] Heberer, T. Stan, H-J. 1997. Detection of more than 50 substituted phenols as their tbutyldimethylsilyl derivatives using gas chromatography-mass spectrometry. Analytica Chimica Acta 341: 21-34.

[7] Minero, C., Maurino, V., Pelizzetti, E. Vione, D. 2007. Assessing the Steady-State $\left[\mathrm{NO}_{2}\right]$ in Environmental Samples. Implication for Aromatic Photonitration Processes Induced by Nitrate and Nitrite. Env Sci Pollut Res 14 (4): 241 - 243.

[8] Sirvent, G., Sanchez, J.M. Salvado, V. 2004. Preconcentration and determination of priority pollutant phenols in waters at trace levels using a polymeric solid-phase extraction cartridge. Journal of separation science 27: 1524-1530.

[9] Sha, Y., Xia , X. Yang, Z. Huang, G.H. 2007. Distribution of PAEs in the middle and lower reaches of the Yellow River, China. Environ Monit Assess 124:277-287.

[10] Adeniyi, A., Dayomi, M., Siebe, P., Okedeyi, O. 2008. An assessment of the levels of phthalate esters and metals in the Muledane open dump, Thohoyandon, Limpopo province, South Africa. Chemistry Central Journal doi:10.1186/1752.153X-2-9.

[11] Parketon, T.F. konkel, W.J. 2000. Application of quantitative structure-activity relationships for assessing the aquatic toxicity of phthalate esters. Ecotoxicology and environmental safety 45:61-78.

[12] Swan, S.H. 2008. Environmental phthalate exposure in relation to reproductive outcomes and other health endpoints in humans. Environmental research 108:177184

[13] Hauser, I. Calafat, 2005. Phthalates and human health. Occupational environmental medical. 62: 806-818

[14] Fatoki, O.S. Noma, A. 2002. Solid phase extraction method for selective determination of phthalate esters in the aquatic environment. Water, Air and Soil Pollution 140: 85-98.

[15] Cespedes, R., Petrovic, M., Raldua, D., Saura, U., Pina, B., Lacorte, S., Viana, P. Barcelo, D. 2004. Integrated procedure for determination of endocrine-disrupting 
activity in surface waters and sediments by use of the biological technique recombinant yeast assay and chemical analysis by LC-ESI-MS. Anal Bioanal Chem 378: 697-708.

[16] Luks-Berlej, K., Popp, P., Janoszka, B. Paschke, H. 2001. Solid-phase microextraction of phthalates from water. Journal of chromatography $A$ 938: 93-101

[17] Cortazar, E., Bartolome, L., Delgado, A., Etxebarria, N., Fern'andez, L.A., Usobiaga, A. Zuloaga, O. 2005. Optimisation of microwave-assisted extraction for the determination of nonylphenols and phthalate esters in sediment samples and comparison with pressurised solvent extraction. Analytica Chimica Acta 534: 247-254.

[18] Kayali, N., Tamayo, F.G. Polo-Diez, L.M., 2006. Determination of dimethylhexyl phthalate in water by solid phase microextraction coupled to high performance liquid chromatography. Talanta 69: 1095-1099.

[19] Trenholm, R.A., Vanderford, B.J., Holady, J.C., Rexing, D.J. Snyder, S.A. 2006. Broad range analysis of endocrine disruptors and pharmaceuticals using gas chromatography and liquid chromatography tandem mass spectrometry. Chemosphere 65: 1990-1998

[20] Marttinen, S., Kettunen, R., Rintala, J. 2003a. Occurrence and removal of organic pollutants in sewages and landfill leachates. Science of the total environment 301:1-12

[21] Roslev, P., Vorkamp, K., Aarap, J., Frederiksen, K. Nielsen, P.H. 2007. Degradation of phthalate esters in an activated sludge wastewater treatment plant. Water research 41:969-976

[22] Vogelsang, C., Grung, M., Jantsch, T.G., Tollefsen, K.E. Liltved, H. 2006. Occurrence and removal of selected organic micropollutants at mechanical, chemical and advanced wastewater treatment plants in Norway. Water research 40:3559-3570

[23] Oliver, R., May, E. Williams, J. 2005. The occurrence and removal of phthalates in a trickle filter STW. Water research 39:4436 - 4444

[24] Ballesteros, O., Zafra, A., Naralon, A. Vilchez, J.L. 2006. Sensitive gas chromatographic -mass spectrometric method for the determination of phthalates esters, alklyphenols, bisphenol A and their chlorinated derivatives in wastewater samples. Journal of chromatography A 1121: 154 -162

[25] Dargnat, C., Teil, M., Chevrevil, M. Blanchard, M. 2009. Phthalate removal throughout wastewater treatment plant case study of Marne Aval station (France). Science of the total environment 407:1235-1244

[26] Saraji, M. Marzban, 2010. Determination of 11 priority pollutant phenols in wastewater using dispersive liquid-liquid microextraction followed by highperformance liquid chromatography-diode-array detection. Anal Bioanal Chem 396:2685-2693

[27] Olujimi, O.O., Fatoki, O.S. and Odendaal, J.P. 2010. Method development for simultaneous determination of phthalate and eleven priority phenols as tertbutyldimethylsilyl derivatives in grab samples from wastewater treatment plants using GC-MS (In press).

[28] Sprynskyy, M., Lebedynets, M., Namiesnik, J. and Buzewski, B. 2007. Phenolic occurrence in surface water of the Dniester basin (West Ukraine): natural background and industrial pollution. Environmental Geology 53:63-75

[29] Bespamyatnov, G.P. and Krotov, Y.A. 1985. Maximum allowable concentrations of chemical substances in environment. Gidrometeoizdat, Leningrad 2 (In Russian)

[30] Finkel'shtejn, A.I., Aref'jeva, R.P. Volkowa, T.A. 1987. Extraction spetrophotometric analyses of low concentration of phenols in wastewater. Khmicheskaya promyshlenost Vol.3:22-23 (In Russian) 
[31] Ge, J., Cong, J., Sun, Y., Li, G., Zhou, Z., Qian, C., Liu, F. 2010. Determination of endocrine disruoting chemicals in surface water and industrial wastewater from Beijing, China. Bull. Environ Contam Toxicol 84:401-405

[32] Sun, Q., Deng, S., Huang, J., Shen, G. and Yu, G. 2008. Contributors to estrogenic activity in wastewater from a large wastewater treatment plant in Beijing, China. Environmental Toxicology and pharmacology 25:20-26 